REGARDS

SUR LEECONOMIE ALLEMAND

BULLETIN ECONOMIQUE DU CIRAC
Regards sur l'économie allemande

Bulletin économique du CIRAC

$78 \mid 2006$

Varia

\title{
De la sortie de crise à la refondation sociale
}

René Lasserre

\section{OpenEdition}

Journals

Édition électronique

URL : http://journals.openedition.org/rea/538

DOI : 10.4000/rea.538

ISBN : 978-2-8218-0852-2

ISSN : 1965-0787

Éditeur

CIRAC

Édition imprimée

Date de publication : 1 octobre 2006

Pagination : 1-2

ISSN : 1156-8992

Référence électronique

René Lasserre, "De la sortie de crise à la refondation sociale», Regards sur l'économie allemande [En ligne], 78 | octobre 2006, mis en ligne le 24 avril 2008, consulté le 22 septembre 2020. URL : http:// journals.openedition.org/rea/538 ; DOI : https://doi.org/10.4000/rea.538 


\section{De la sortie de crise à la refondation sociale}

Tous les signaux indiquent que l'Allemagne a réussi à surmonter le processus de stagnation économique dans lequel elle était engluée depuis dix ans et qu'elle est maintenant sortie de la crise. La reprise économique est solidement installée et vigoureuse : la croissance dépasse les prévisions les plus optimistes, les tous derniers indices confirment que la production industrielle tourne à plein régime sous le double effet d'une demande mondiale soutenue et d'une forte dynamique interne de l'investissement. La demande intérieure, longtemps balbutiante, est maintenant en plein boom et se nourrit désormais de la reprise de l'emploi et du recul tangible du chômage. Forte de cette dynamique et d'une confiance retrouvée, l'économie allemande devrait pouvoir absorber sans soubresaut le coup de froid tant redouté de la hausse de la TVA au 1 er janvier.

A la faveur de l'embellie conjoncturelle, mais aussi au crédit de la détermination politique du gouvernement de coalition et de la responsabilité des partenaires sociaux, les fondamentaux de l'économie sont en voie de consolidation : le retour du déficit public très nettement en dessous de la barre des $3 \%$ est d'ores et déjà acquis et l'assainissement des finances publiques est en bonne voie. Il reste cependant encore à l'établir sur des bases économiques durables : non seulement en élargissant l'assiette des prélèvements sur la consommation mais en réformant la fiscalité au profit de la création de richesse et, mieux encore, en réduisant les dépenses. Plus décisive encore est la restructuration en profondeur des régimes sociaux et de leurs bases de financement. La coalition gouvernementale s'est résolument attaquée à ces chantiers de fond et a défini des orientations courageuses sur le dossier crucial de la réforme des retraites. Il n'en reste pas moins que dans la réalisation de son programme, elle n'en est qu'à mi-chemin et que, à l'instar du projet de réforme du système de santé, de sérieux tiraillements se font jour entre les deux partis de la coalition et peuvent conduire au blocage.

Si elle n'est pas exclure, cette hypothèse n'est cependant pas la plus probable. Le coup de semonce de l'élection de l'automne 2005 qui a finalement contraint les deux grands partis à affronter ensemble les grands défis du pays a conduit ces derniers à engager parallèlement une révision de leurs programmes fondamentaux, ce qui indique que chacun se place résolument dans une perspective à moyen terme. A priori banal et convenu, l'exercice n'est pourtant pas de simple circonstance: les deux formations se sont engagées dans une réflexion politique de fond qui doit déboucher à l'automne 2007 sur la présentation de leur vision respective de l'avenir de l'Allemagne. Au-delà de son caractère formel, le processus de réflexion qui s'est ainsi engagé mérite qu'on s'y arrête car il apparaît riche d'enseignements sur la façon dont la société politique allemande se projette dans l'avenir. Car c'est bel et bien à une refondation du modèle économique et social allemand que se sont attaqués les deux grands partis démocratiques. 
Avec ceci de singulier, mais pas totalement inattendu, que dans leurs orientations les deux projets sont finalement assez proches. Loin de céder à la facilité d'un affrontement gauche-droite stérile et de s'arcbouter sur des positions doctrinales traditionnelles, prônant d'un côté la rupture libérale et de l'autre la conservation d'un Etat social ruineux, chacun des deux partis s'attache à dessiner la voie d'une réforme nécessaire et souhaitable dans laquelle l'ensemble des Allemands puissent se retrouver. Ainsi se dégage, par delà des accents nécessairement différents, un consensus de fond sur quelques grands principes d'une société citoyenne fondée sur la liberté et la responsabilité individuelles, la première devant promouvoir l'initiative créatrice de l'individu, tandis que la seconde doit le conduire à prendre en charge une part plus grande de sa formation et de sa protection. Consensus aussi sur la réforme et le redéploiement nécessaires de l'Etat dont les efforts devront davantage se porter vers la préparation de l'avenir et la prévention sociale que de s'enliser dans un interventionnisme multiforme, à la fois coûteux et paralysant. Consensus encore sur une économie de marché ouverte à la globalisation, clé de la performance économique, mais respectant les droits sociaux fondamentaux. Consensus enfin sur l'Europe, appelée à devenir le cadre naturel d'un libéralisme organisé et d'un modèle social partagé.

On le voit : l'Allemagne n'est pas seulement sortie de la crise, elle est d'ores et déjà en train de reconstruire son modèle économique et social sur des bases rénovées. 